\title{
Study of Hemodynamics of Orbital Arterial Vasculature in Moderate-Severe Thyroid Associated 0phthalmopathy and its Correlation with Disease Activity
} \author{
Saxena $^{4}$ and Sandeep Saxena ${ }^{1}$ \\ ${ }^{1}$ Department of Ophthalmology, King George's Medical University, India \\ ${ }^{2}$ Department of Radiodiagnosis, King George's Medical University, India \\ ${ }^{3}$ Department of Endocrinology, King George's Medical University, India \\ ${ }^{4}$ Department of Cytogenetics, King George's medical university, India
}

Sukriti Ahuja ${ }^{1 *}$, Apjit Kaur ${ }^{1}$, Manoj Kumar ${ }^{2}$, Harsh Singh ${ }^{2}$, Vinita Singh ${ }^{1,}$ Madhukar Mittal ${ }^{3}$, Shailendra K

Submission: February 14, 2019; Published: May 30, 2019

*Corresponding author: Sukriti Ahuja, Department of Ophthalmology King George’s Medical University, Lucknow, Indi

Abstract

Aim: To study the arterial blood flow changes in the orbit in thyroid associated ophthalmopathy (TAO) and compare the blood flow parameters with disease activity.

Design: Observational study

Patients: Fifty consecutive patients of TAO

Measurements: Blood flow parameters in the ophthalmic artery (OA) and central retinal artery (CRA) were measured in fifty consecutive patients of moderate-severe stage TAO (EUGOGO classification), irrespective of disease activity using Color Doppler Imaging. Resistive index (RI) was calculated by the formula: RI= (Pre-Systolic Velocity-End Diastolic Velocity)/ Pre-Systolic Velocity. Discriminant function of RI of OA and CRA to determine the activity of TAO was measured using the area under curve (AUC) values of receiver operator characteristics curve (ROC curve).

Results: Resistive index of OA and CRA was higher in patients of active stage than inactive stage. ROC curve analysis showed excellent predictive accuracy of RI for activity of TAO (AUC of OA=0. $993 \pm 0.007, p<0.05$ and AUC of CRA $=1.00 \pm 0.00, p<0.05$ ).

Conclusion: A significant compromise of arterial vasculature occurs in the active stage of TAO, which only partially resolves in the inactive phase. Resistive index can be used to distinguish between active and inactive stages of the disease, providing proof of additional threat to vision as a result of ischemic compromise.

Keywords: Thyroid associated ophthalmopathy; Resistive index; Pre-systolic velocity; End diastolic velocity; Ophthalmic artery; Central retinal artery; Clinical activity score

Abbreviations: TAO: Thyroid Associated Ophthalmopathy; RI: Resistive Index: OA: Ophthalmic Artery: CRA: Central Retinal Artery; ROC: Receiver Operator Characteristic

\section{Introduction}

Thyroid associated ophthalmopathy (TAO) is an autoimmune inflammatory orbital disorder that follows the Rundle's curve [1]. The orbital tissues undergo changes in active and inactive phase characterized by tissue expansion and fibrosis respectively [2]. The orbital vasculature reflects these changes clinically in all stages. The effects on the orbital venous system are well documented in literature [3]. The authors hypothesize that the changes occurring in the orbital tissues influence the orbital arterial vasculature in both the active and inactive phase of TAO. With this hypothesis, the authors undertook the current study to evaluate the vascular indices of orbital arteries (Ophthalmic artery and Central retinal 
artery) in patients with moderate-severe TAO and examine the correlation of the arterial changes with the stage of the disease. Color Doppler imaging was used to study the hemodynamics of the, Ophthalmic artery and Central retinal artery. Record of the peak systolic velocity (PSV) and end diastolic velocity (EDV) over the cardiac cycle were used calculate the Resistive Index (RI) of the arteries.

\section{Methods}

The authors confirm adherence to the tenets of the Declaration of Helsinki. An institutional review board clearance was obtained. Informed voluntary consent was taken from all the study subjects. An observational study was conducted at the Oculoplastic and orbit unit, Department of Ophthalmology, King George's Medical University, Lucknow for a period of one year. Fifty consecutive patients of moderate-severe thyroid associated ophthalmopathy were recruited. Grading of moderate-severe TAO was based on EUGOGO classification system [4]. 27 females and 23 males with mean age $39.2 \pm 8.3$ years were the study subjects. Disease activity was evaluated using the clinical activity score (CAS score) [5]. A CAS score of more than 3 was considered as active disease stage. Patients with co-morbidities of the orbit (trauma, non-specific orbital inflammatory diseases, any orbital mass), who underwent an ocular surgery, had been treated with iodine 131, were not included in the study. Color Doppler imaging (CDI) was done in the Department of Radiodiagnosis, King George's Medical University, Lucknow using the Philips Affiniti 70G Ultrasound System, Vista, California (USA). Blood flow was studied in the ophthalmic artery (OA) and Central retinal artery (CRA) of both sides. The Pre-systolic velocity (PSV) and End Diastolic velocity (EDV) were recorded in each patient in supine position for both the arteries. Two experienced radiologists masked to the stage of TAO assessed resistive index (RI) of OA and CRA separately. Average of values for each case was considered. The vascular resistance against blood flow was calculated by the following formula: RI= (PSV-EDV)/PSV.

\section{Statistical Analysis}

Mean values were calculated for EDV, PSV and RI separately for CRA and OA. The Receiver operator characteristic curve (ROC curve) was computed for the RI of OA and CRA with CAS score. The area under the curve to discriminate the RI in active and inactive disease was calculated. Interobserver correlation was computed using Spearman rank correlation. Test was significance used was unpaired T test. $\mathrm{p}<0.05$ was taken as significant.

\section{Results}

Data of 50 consecutive patients of TAO was statistically analyzed. Patients of active disease $(n=29)$ showed a significant decrease of both mean PSV and mean EDV. Their mean RI was significantly higher than that of patients of inactive stage $(p<0.05)$ (Table 1). Discriminant value of RI of OA and CRA for activity of the disease was evaluated using receiver operator characteristic curve (ROC). The ROC curve analysis showed diagnostic accuracy of RI of OA [Area under curve (AUC) $=0$. $993 \pm 0.007, p<0.05]$ in discriminating between active and inactive disease (Figure 1). The ROC curve analysis also revealed significant diagnostic accuracy of RI of CRA (AUC $=1.00 \pm 0.00$, $\mathrm{p}<0.05$ ) in discriminating between active and inactive disease (Figure 2).

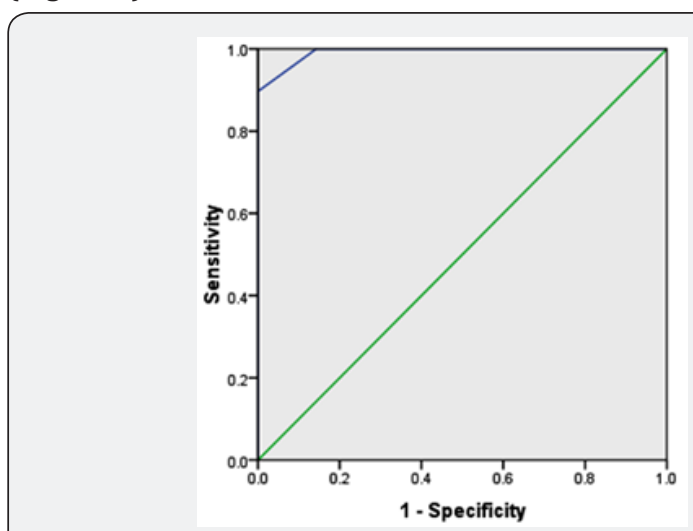

Figure 1: ROC curve showing the discriminant value of RI of $\mathrm{OA}$ to distinguish between the active and inactive stage of the disease $(A \cup C=0.993 \pm 0.007(95 \%, C l 0.978-1.007, P<0.001)$

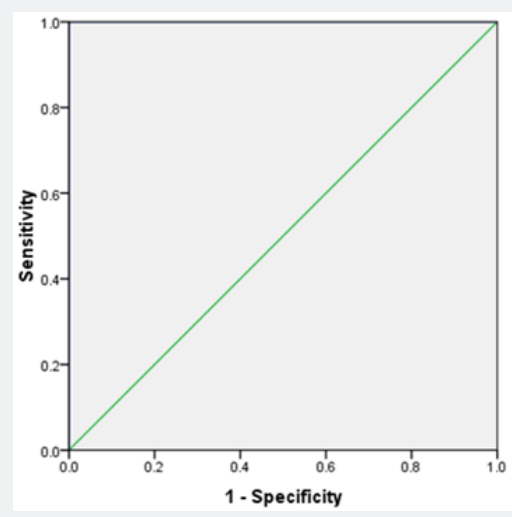

Figure 2: ROC curve showing the discriminant value of RI of CRA to distinguish between the active and inactive stage of the disease $(A \cup C=1.00 \pm 0.00, p<0.001)$

Table 1: Hemodynamic characteristics of active and inactive disease stage.

\begin{tabular}{|c|c|c|c|c|c|}
\hline Study group (n=50) & $\begin{array}{c}\text { Mean PSV of OA } \\
\text { (cm/s) }\end{array}$ & $\begin{array}{c}\text { Mean PSV of CRA } \\
\text { (cm/s) }\end{array}$ & $\begin{array}{c}\text { Mean EDV of OA } \\
\text { (cm/s) }\end{array}$ & $\begin{array}{c}\text { Mean EDV of CRA } \\
\text { (cm/s) }\end{array}$ & Mean RI of OA \\
\hline $\begin{array}{c}\text { Active stage (n=29) } \\
\text { (CAS>3) }\end{array}$ & $28.03 \pm 6.7$ & $9.9 \pm 0.66$ & $5.23 \pm 1.7$ & $2.71 \pm-0.78$ & $0.82 \pm 0.029$ \\
\hline $\begin{array}{c}\text { Inactive stage disease } \\
(\mathrm{n}=21 \text { ) (CAS</=3) }\end{array}$ & $38.09 \pm 5.7$ & $16.9 \pm 0.56$ & $9.8 \pm 2.9$ & $5.78 \pm 0.45$ \\
\hline
\end{tabular}

PSV: Peak systolic velocity; OA: Ophthalmic artery; EDV: End diastolic velocity; CRA: Central retinal artery; CAS: Clinical activity score 


\section{Discussion}

TAO is characterized by changes in the orbital tissues, both in active and inactive stages [6]. The changes in the orbital venous system due to TAO have been adequately documented in literature [7]. The expanded soft orbital tissues displace the globe forward and impede orbital venous outflow. Thus, leading to orbital venous congestion and decreased blood flow velocity in superior ophthalmic vein [8]. The authors hypothesize that TAO induced changes in orbital tissues also affect the orbital arterial vasculature in both the active and inactive phase of the disease. The inflamed orbital tissues in the active stage probably have an extrinsic compressive effect on the blood vessels. As the disease progresses into the fibrotic phase, the inflammatory edema subsides. However, the occurrence of fibrotic changes in the tissues surrounding the blood vessels continues to impede the blood flow. Color Doppler imaging (CDI) has been harnessed as a non-invasive technique to determine the changes in the orbital hemodynamics. The vascular resistance is determined by resistive index, with vascular compliance considered.

Normal baseline values of PSV in OA and CRA is $45.3 \pm 10.5$ and $17.3 \pm 2.6 \mathrm{~cm} / \mathrm{sec}$ respectively, whereas normal values of EDV in OA and CRA is $11.8 \pm 4.3$ and $6.2 \pm 2.7 \mathrm{~cm} / \mathrm{sec}$ respectively. The normal value of RI of OA $(0.70 \pm 0.05)$ and CRA $(0.64 \pm 0.07)$ [9]. Data analysis of the study showed that the mean PSV and EDV of both OA and CRA significantly decrease in the active disease stage as compared to inactive stage. RI of OA and CRA an incremental trend in the active stage of TAO. The mean RI of OA in active disease patients was $0.82 \pm 0.09$ and RI of CRA was 0.77 \pm 0.034 . A significant decrease in the RI of OA and CRA occurs in the inactive stage. However, the difference of RI between inactive stage and normal baseline data provided in literature do not show statistically significant difference. Discriminant function of RI of OA and CRA to determine the activity of TAO was measured using the ROC curve. AUC values showed an excellent predictive accuracy of RI of both OA and CRA for activity of TAO. Thus, RI can be used to distinguish between active and inactive disease stages. Earlier studies on vascular parameters of OA and CRA have shown varied results.

A study by Yanik et al. [10] concluded that PSV and EDV measured in the ophthalmic artery and central retinal artery were considerably higher in patients with CAS $>3$ compared with patients with CAS 0 and CAS $1-2$ as well as healthy controls. The RI in the ophthalmic artery was considerably lower than in controls. Higher arterial flow velocities and lower RIs of OA were observed in patients with high clinical activity score. Orbital inflammatory activity was primarily responsible for the blood flow alterations [10].

Alp et al. showed similar results in their study. The velocities in the OA and CRA were found to be higher in patients with TAO than in patients without ophthalmopathy with grave's disease or in healthy controls [11]. Both these studies concluded that RI of OA and CRA decreases in the active disease. These results contrast with the results obtained in the present study. Indirect evidence supporting our study findings is acknowledged from the report by Peres Lopez et al. [12]. They observed that there was a decrease in RI of OA and CRA after surgical decompression. Because decompression surgery resolves the orbital space conflict and decreases the orbital pressure in TAO, the decreased RIs of both the OA and CRA after surgery may be consistent with resolved vascular extrinsic compression.

Similar effect of external compression of the increased intraorbital pressure leading to increased RI in active disease has been hypothesized in the present study. Area under curve values also showed excellent predictive value of RI of both OA and CRA to discriminate between active and inactive stages of the disease. Thus, the present study demonstrates the significant orbital arterial vasculature changes occurring in the active stage of the disease. These changes subside as the active inflammatory phase is over in the inactive stage. The results of the current analysis confirm the study hypothesis that TAO causes changes in orbital arterial blood flow both in active and inactive phase of the disease. This may have a bearing on the future course of events in the disease as the impeded arterial blood flow could contribute to inducing ischemic changes in an optic nerve that is under threat of compressive changes (compressive neuropathy). Thus, the authors suggest an evaluation of the Resistive index of the Ophthalmic artery and Central Retinal artery in active and inactive phase of the disease. This would identify the additional compromise. Also, further studies could be indicated to analyze the role of vasodilators to overcome the impeded flow. The lack of normative data of orbital vascular hemodynamics from our population is a possible limitation of this study.

\section{Conclusion}

A significant compromise of arterial vasculature occurs in the active stage of TAO, which only partially resolves in the inactive phase. Resistive index can be used to distinguish between active and inactive stages of the disease, providing proof of additional threat to vision as a result of ischemic compromise.

\section{References}

1. Marcoccic, Bartalena L, Bogazzi F, Panicucci M, Pinchera A (1989) Studies on occurrence of ophthalmopathy in Graves' disease. Acta Endocrinol (Copenh) 120(4): 473-478.

2. Burch HB, Wartofsky L (1993) Graves' ophthalmopathy: current concepts regarding pathogenesis and management. Endocr Rev 14(6): 747-793.

3. Kilicarslan R, Alkan A, Ilhan MM, Yetis H, Aralasmak A, et al. (2015) Graves' ophthalmopathy: the role of diffusion-weighted imaging in detecting involvement of extraocular muscles in early period of disease. The British journal of radiology 88(1047): 20140677.

4. Bahn R (2008) The EUGOGO consensus statement on the management of Graves' orbitopathy: equally applicable to North American clinicians and patients. Thyroid 18(3): 281-282.

5. Mourits MP, Koornneef L, Wiersinga WM, et al. (1989) Clinical criteria for the assessment of disease activity in Graves' Ophthalmopathy: A novel approach. Br J Ophthalmol 73(8): 639-644. 
6. Wiersinga WM, Prummel MF (2001) Pathogenesis of Graves' ophthalmopathy_current understanding. J Clinic Endocrinol Metab 86(2): 501-503.

7. Ohnishi T, Noguchi S, Murakami N, Tajiri J, Harao M, et al. (1994) Extraocular muscles in Graves' opthalmopathy: usefulness of T2 relaxation time measurements. Radiology 190(3): 857-862.

8. Bartalena L, Pinchera A, Marcocci C (2000) Management of Graves Ophthalmopathy: Reality and Perspective. Endocrine Reviews 21(2) 168-199.

9. Tranquart F, Berges O, Koskas P (2003) Color Doppler imaging of orbital vessels: personal xperience and literature review. J Clin Ultrasound 31(5): 258-273.

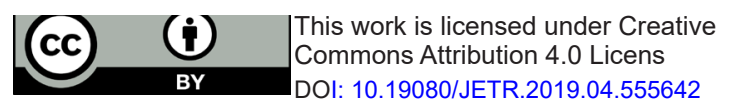

10. Yanik B, Conkbayir I, Acaroglu G, Hekimoglu B (2005) Graves' ophthalmopathy: comparison of the Doppler sonography parameters with the clinical activity score. J Clin Ultrasound 33(8): 375-380.

11. Alp MN, Ozgen A, Can I, Cakar P, Gunalp I (2000) Colour Doppler imaging of the orbital vasculature in Graves' disease with computed tomographic correlation. Br J Ophthalmol 84(9): 1027-1030.

12. Pérez-López M, Sales-Sanz M, Rebolleda G, Casas-Llera P, GonzálezGordaliza C, et al. (2011) Retrobulbar ocular blood flow changes after orbital decompression in Graves' ophthalmopathy measured by color Doppler imaging. Invest Ophthalmol Vis Sci 52(8): 5612-5617.

\section{Your next submission with Juniper Publishers will reach you the below assets}

- Quality Editorial service

- Swift Peer Review

- Reprints availability

- E-prints Service

- Manuscript Podcast for convenient understanding

- Global attainment for your research

- Manuscript accessibility in different formats

(Pdf, E-pub, Full Text, Audio)

- Unceasing customer service

Track the below URL for one-step submission https://juniperpublishers.com/online-submission.php 